\title{
Health related quality of life of immigrant children: towards a new pattern in Germany?
}

\author{
Ester Villalonga-Olives ${ }^{1,2^{*}}$, Nicole von Steinbüchel ${ }^{1}$, Claudia Witte ${ }^{1}$, Erich Kasten ${ }^{1}$, Ichiro Kawachi ${ }^{2}$ \\ and Christiane Kiese-Himmel ${ }^{1}$
}

\begin{abstract}
Background: To study Health related quality of life (HRQoL) of a sample of kindergarten children with migration background.

Methods: Five kindergartens in Frankfurt/Main and Darmstadt (Germany) participated. HRQoL was measured with the Kiddy-KINDL (KK) in 3 to 5 year old children. We examined the associations of HRQoL with socio-demographic variables, positive development and resilience, socio-emotional and motor development. Linear regression models were applied to examine differences in HRQoL between migrant and native-born German children.

Results: The response rate was $90.5 \%(\mathrm{~N}=283)$. The children had predominantly migrant background (81.35\%). Perceived health was slightly higher in migrants (69.85, SD 17.00) compared to native-born German children (68.33, SD 17.31, $p>0.05)$, even though migrant children were characterized by a lower socio-economic status $(p<0.01)$.

Conclusions: Results suggest that HRQoL at early ages in our study exhibits a different pattern than reported previously in studies among older individuals. We attribute the discrepancy partly to a possible changing pattern of migration in Europe with more migrants capable to migrate with healthy profiles, and to the age of our population. Our findings underscore the need to study the life course trajectory of HRQOL among young immigrants and replication in representative samples.
\end{abstract}

Keywords: Health related quality of life, Kindergarten children, Life course, Migrants, Migrant health paradox

\section{Background}

Migration has increased since the beginning of the worldwide economic crisis in 2008, and it is a topic of bigger interest [1]. Within the European Union (EU), data suggest that children with migrant backgrounds have lower health status than native-born populations [2-5]. These differences have been attributed to the lower socio-economic backgrounds of economic migrants, lack of social integration, deficits in second language competence and performance as well as to experiences of discrimination [6]. This pattern is in contrast to studies conducted in the United States where immigrants - particularly Mexican-Americans have been found to have better health outcomes (e.g. a lower number of children with low birth weight rates)

\footnotetext{
* Correspondence: ester.villalonga@gmail.com

'Department of Medical Psychology and Medical Sociology, University Medical Center, Georg-August-University, Göttingen, Germany

${ }^{2}$ Department of Social and Behavioral Sciences, Harvard School of Public Health, Boston, MA 02215, USA
}

compared to the native-born, in spite of their lower socioeconomic backgrounds.

The so-called "Latino health paradox" in the United States has been in turn ascribed to selective migration [7-10]. In other words, economic migrants constitute a healthy group of individuals who are fit to work, and often exhibit better health status than native-born individuals in spite of their socio-economic disadvantage. However, more recent migrants into the US tend to be families with job skills [11]. Considering the evolving reasons for migration over time (the "migration regime"), we hypothesize that the profile of migrants may have changed, making the patterns more similar to that observed in the United States with a profile of people with low socio-economic factors but with good job skills. Facts like the south-north migration, the levels of unemployment in the EU, and the good health status reported by migrants from Eastern and Mediterranean countries in some studies can be related to this phenomenon [12]. 
In contrast to the force of selective migration, there are opposite tendencies that tend to lower the health of migrant groups. Thus the migration process itself has been linked to family stress and lack of social support in the offspring of migrant families $[13,14]$. But the effect of the migration process can also vary depending on the age of the children. Health related quality of life (HRQoL) is a concept which represents a person's own perception of his or her subjective health status, functioning, and well-being in the domains of physical, psychological, social and role performance $[15,16]$. Given the rise in immigrant populations, and the suggestion of a possible recent change in the migration pattern across the EU, it is of interest to measure the impact of the migratory experience on health and HRQoL of migrants, especially children.

Germany is one of the countries that received an increasing number of migrants from other countries seeking work. There are 1.14 million children under the age of five from migrant backgrounds currently living in Germany [17], representing $34.84 \%$ of children in that country. Studies have found that there are HRQoL differences between migrants and native-born depending on age, gender and socio-economic status [18-20]. Schenk and co-authors noted in 2008 that migrant parents in Germany rated the HRQoL of their children (aged 3-10 years) significantly lower than native-born parents [21]. However, there are only very few studies in European countries that compare HRQoL in children of migrant versus native-born populations [20,22]. Indeed, there are neither reports with recent data; nor data from young children using self-reports.

In Germany, 34.84\% of children between 3 to 5 years old have migrant backgrounds. In metropolitan areas, the prevalence is even higher and ranges from 45 to $65 \%$ [23]. However, there are no studies yet that have investigated the HRQoL of this population; our objective was therefore to study a sample of migrant children. We hypothesized that young migrant children would report lower HRQoL than native-born children because of the stress of dislocation as well as their disadvantaged social background. We hypothesized that HRQoL is influenced by socio-economic variables, positive development and resilience, socio-emotional and motor development, and that these will differ between migrants and native-born.

\section{Methods}

\section{Design, sample and procedure}

The population of the study comprised the baseline data of a longitudinal study whose main aim was to investigate health outcomes in children from 3 to 5 years old with predominantly migrant backgrounds, and to assess the development of these children. The baseline study was conducted in Frankfurt/Main and Darmstadt, Germany. Five kindergartens located in five areas of education pertaining to different neighborhoods accepted to take part in the study. Participants were enrolled at the kindergartens and $96 \%$ of the parents consented to take part in the study $(\mathrm{N}=300)$. Among these children, $81.35 \%$ had at least one parent coming from another country (second generation migrants). Data collection started in May 2009 and it is still ongoing. The response rate out of the whole was $90.5 \%(\mathrm{~N}=283)$. The project was approved by the local ethics committee of the University Medical Center, Göttingen, Germany.

Informed consent was obtained from participating families, with the approval of the kindergarten councils. Families received detailed information regarding the background and implementation of the study and were offered the opportunity to withdraw the participation of their children at any time. Interviewers were trained in person by the scientists who designed the study project and had a manual to follow the detailed instructions. The collection of data was performed using face to face interviews with children, parents and teachers, separately.

\section{Measures}

\section{Socio-demographic and socio-economic variables}

We collected information about occupation and level of education of the main sustainer of the family to characterize the family's socio-economic status. Here the international ISCO categorization was followed. To perform the analysis of these data, we created a final categorical variable: out of work (0), unskilled workers (1), skilled workers (2), professionals (3) and professionals with advanced qualifications (4). Socio-economic status data were collected by psychologists and educators during an interview with the parents.

\section{Kiddy-KINDL (KK)}

The Kiddy-KINDL is a validated and reliable instrument developed in Germany to measure HRQoL in children aged between 4 and 7 years [24-26]. The recall period of the questionnaire is the past week. The short version of this questionnaire includes 12 items belonging to $6 \mathrm{di}$ mensions: physical well-being, psychological well-being, self-esteem, family, friends, and everyday functioning at the kindergarten. Response categories are arranged on a 3-point Likert scale (never; sometimes; very often). Scale scores of the KK range from 0 to 100, with higher scores indicating better HRQoL. We administered the self-report version of the KK to children aged 3 to 5 years. Psychometric properties of the instrument were found to be acceptable in this sample [Villalonga-Olives E, Witte C, Almansa J, Lange B, Hacker K, Dusilova I, Kiese-Himmel C, Von Steinbüchel N: Self-reported health-related quality of life in kindergarten children: psychometric properties of the Kiddy-KINDL. Submitted]. The KK was administered by psychologists and educators using face-to-face interviews with the children. The interviewers were previously trained. 


\section{Positive development and resilience in daily life of kindergarten children (PERIK)}

The PERIK is a German instrument designed to observe and assess the preschool children's well-being in early childhood settings of children aged 3.5 to 5 years of age. The questionnaire contains 36 items, distributed in 6 scales of 6 items each: interpersonal skills, self-monitoring/thoughtfulness, assertiveness, resilience, task oriented behavior, and enjoyment in exploratory behavior. The responses are arranged along a five-point rating-scale (always; mostly; sometimes; rarely; never). The values range from 0 to 30 . Higher scores indicate better performance. The instrument has been demonstrated to have acceptable psychometric properties [27]. We have used the scale of PERIK that measures positive development and resilience, because it has been related to the concept of HRQoL and the experience of major life events like migration; the KK does not contain this facet. PERIK was answered by the kindergarten teachers.

\section{Vienna developmental test (WET)}

The WET is a widely used instrument which measures the developmental status of children aged 3 to 6 years [28]. The WET consists of 13 subtests and a parent questionnaire, covering 6 functional areas of development (visual, motor, learning/memory, cognitive stage, language, and socioemotional developmen). The variables range from 0 to 9 , with higher scores indicating better development. The instrument has good face validity and good construct validity: factor reproduction of the dimensions, and increasing performance with increasing age ("age trend"). We have used the scales socio-emotional and motor development of WET, because they have been related to the concept of HRQoL and showed a significant relationship with HRQoL in preliminary analysis [29-31]. WET was administered and tested by psychologists and educators using face-to-face interviews with parents and children.

In sum, we collected subjective measures (self-perception), a parental assessment and professional assessments of psychologists and kindergarten teachers to have a more appropriate perspective.

\section{Statistical analysis}

Descriptive analyses were conducted stratifying by gender. Migrant and native-born children were compared with respect to HRQoL as well as the other study variables using t-tests to assess mean differences. We fit a multiple linear regression model with age, gender, positive development and resilience, socio-emotional and motor development, adjusted for socio-economic conditions and area of education. We separated migrants and native-born and investigated the relationship of these factors with HRQoL.
For this study only baseline data were used. Missing data were imputed by substituting for the missing value the scale mean rounded to an integer. Means for all instruments used in the analysis were calculated if up to $33 \%$ of responses were missing. For analysis, SAS software was used [32].

\section{Results}

Gender was approximately equally distributed in the present sample (50.9\% girls) (Table 1$)$. The mean age in years was 4.25 (SD 0.88) for boys and 4.25 (SD 0.82) for girls. In $72 \%$ of families both parents were born outside of Germany, 9.3\% had one parent born outside Germany and $18.5 \%$ had both parents born in Germany. We did not have the information of origin of 4 families that were part of the study, and who could not be classified.

Fathers were predominantly the main economic providers of the family. The origin of the migrant families was heterogeneous. The largest group of children came from Asia (especially from Turkey) with $42.8 \%$ and the second largest group from Africa representing 35.2\% (mostly from Ghana and Morocco); the third group was from Eastern Europe (mostly from Bosnia, Bulgaria, Russia and Albania) constituting $10.1 \%$ of the whole study population (Table 1 ).

We found statistically significant differences between migrant and native-born children in their socio-economic status $(p=0.00)$. Results showed migrants to have lower socio-economic levels. But no statistically significant differences were found among groups in the other study variables (Table 2). HRQoL was slightly higher in migrants, but these differences were not statistically significant comparing

Table 1 Descriptive statistics of the study sample

\begin{tabular}{lcc}
\hline & Boys & Girls \\
& N=139 & $\mathbf{N}=144$ \\
Mean [percentage] & Mean [percentage] \\
\hline Nigrant families & {$[79.7 \%]$} & {$[83.0 \%]$} \\
Age & {$[20.3 \%]$} & {$[17.0 \%]$} \\
Area of education & $4.25($ SD 0.88$)$ & $4.25($ SD 0.82$)$ \\
St Gallus & & \\
St Pius & {$[25.2 \%]$} & {$[30.6 \%]$} \\
St Fidelis & {$[19.4 \%]$} & {$[14.6 \%]$} \\
St. Martin & {$[17.3 \%]$} & {$[16.0 \%]$} \\
St. Michael & {$[15.1 \%]$} & {$[17.4 \%]$} \\
Origin of migrant families: & {$[23.0 \%]$} & {$[21.4 \%]$} \\
Asia & & \\
Africa & {$[40.2 \%]$} & {$[45.5 \%]$} \\
Eastern Europe & {$[40.2 \%]$} & {$[30.3 \%]$} \\
Western Europe & {$[15.2 \%]$} & {$[5.1 \%]$} \\
North and South America & {$[3.3 \%]$} & {$[15.2 \%]$} \\
\hline
\end{tabular}


Table 2 Mean score and standard deviation (SD) of study variables for migrant and native-born children

\begin{tabular}{|c|c|c|c|c|c|}
\hline \multirow[t]{2}{*}{ Variables } & \multicolumn{2}{|c|}{$\begin{array}{c}\text { Migrant } \\
(\mathrm{N}=227)\end{array}$} & \multicolumn{2}{|c|}{$\begin{array}{l}\text { Native-born } \\
(\mathrm{N}=52)\end{array}$} & \multirow[b]{2}{*}{ Significance } \\
\hline & $\begin{array}{c}\text { Mean } \\
{[\%]}\end{array}$ & (SD) & $\begin{array}{c}\text { Mean } \\
{[\%]}\end{array}$ & (SD) & \\
\hline HRQoL & 69.85 & $(17.00)$ & 68.33 & (17.31) & 0.39 \\
\hline $\begin{array}{l}\text { Positive development } \\
\text { and resilience }\end{array}$ & 21.06 & $(4.15)$ & 21.37 & $(4.60)$ & 0.52 \\
\hline $\begin{array}{l}\text { Socio-emotional } \\
\text { development }\end{array}$ & 4.48 & $(2.58)$ & 4.84 & $(2.04)$ & 0.54 \\
\hline Motor development & 5.89 & $(2.39)$ & 5.44 & $(2.64)$ & 0.13 \\
\hline \multicolumn{6}{|l|}{ Socio-economic status } \\
\hline $\begin{array}{l}\text { Professionals with } \\
\text { advanced qualifications }\end{array}$ & {$[10.5 \%]$} & & {$[40.5 \%]$} & & 0.00 \\
\hline $\begin{array}{l}\text { Skilled non manual } \\
\text { workers }\end{array}$ & [11.5\%] & & {$[23.8 \%]$} & & \\
\hline Skilled manual workers & {$[47.4 \%]$} & & {$[23.8 \%]$} & & \\
\hline Unskilled workers & [20.1\%] & & {$[4.8 \%]$} & & \\
\hline Out of work & [10.5\%] & & [7.1\%] & & \\
\hline
\end{tabular}

Significance measured with t-tests.

migrants to native-born. Girls reported higher HRQoL compared to boys, especially in native-born (Table 3). Gender differences were statistically significant on the t-tests in the overall sample.

Table 4 presents the results of the multiple linear regression. Among migrants, age showed almost significant associations with HRQoL ( $\mathrm{p}=0.07)$. By contrast, no differences were observed among migrants and nativeborn.

\section{Discussion}

The purpose of this study was to assess HRQoL in children predominantly with migrant backgrounds. We hypothesized that despite the possible changes in the migration regime in recent years, migrant children would report lower HRQoL because of the stress of dislocation of the family and their social background. However, we found no important differences in HRQoL scores among migrants and native-born children. If anything, migrant children seemed

Table 3 Mean score and standard deviation (SD) of HRQoL (Kiddy-KINDL) for migrants and native-born and stratifying by gender

\begin{tabular}{|c|c|c|c|c|c|c|}
\hline & \multicolumn{2}{|c|}{$\begin{array}{c}\text { Total } \\
\mathrm{N}=\mathbf{2 8 3}\end{array}$} & \multicolumn{2}{|c|}{$\begin{array}{c}\text { Boys } \\
N=139\end{array}$} & \multicolumn{2}{|c|}{$\begin{array}{c}\text { Girls } \\
N=144\end{array}$} \\
\hline & Mean & (SD) & Mean & (SD) & Mean & (SD) \\
\hline Migrants & 69.85 & $(17.00)$ & 68.12 & (17.64) & 71.51 & (16.23) \\
\hline Native-born & 68.33 & (17.31) & 64.29 & (17.74) & 73.08 & (15.87) \\
\hline Overall & $69.09^{*}$ & (17.51) & 66.20 & (17.69) & 72.29 & (16.05) \\
\hline
\end{tabular}

Note: *Overall was calculated with $\mathrm{N}=279$ due to missing data at the classification of migrants and native-born; the $t$-test showed statistically significant differences between boys and girls in the overall sample.
Table 4 Multiple linear regression model of HRQoL (Kiddy-KINDL) for migrants and native-born

\begin{tabular}{|c|c|c|c|c|c|c|}
\hline & \multicolumn{3}{|c|}{ Migrants } & \multicolumn{3}{|c|}{ Native-born } \\
\hline & B & SE & $\overline{\text { t significance }}$ & B & SE & t significance \\
\hline Age & 0.47 & 2.20 & 0.82 & 3.73 & 4.51 & 0.41 \\
\hline Gender & 4.50 & 2.54 & 0.07 & 6.05 & 5.30 & 0.26 \\
\hline $\begin{array}{l}\text { Positive } \\
\text { development } \\
\text { and resilience }\end{array}$ & -0.25 & 0.30 & 0.40 & 0.15 & 0.58 & 0.79 \\
\hline $\begin{array}{l}\text { Socio-emotional } \\
\text { development }\end{array}$ & -0.11 & 0.59 & 0.84 & -2.14 & 1.59 & 0.18 \\
\hline $\begin{array}{l}\text { Motor } \\
\text { development }\end{array}$ & 1.08 & 0.77 & 0.16 & 0.32 & 1.34 & 0.33 \\
\hline
\end{tabular}

Note: The model was adjusted for area of education and socio-economic status.

to report slightly higher perceived health than native-born children, and girls tended to report higher HRQoL compared to boys, especially in native-born children. Our findings differ from those reported in previous studies in which migrants have been found to report worse subjective health compared to the native-born [3,5]. However, the differences between the instruments applied in the studies limit the comparison of the findings.

We found significant differences in socio-economic status between migrants and native-born children, where migrants had lower levels. Despite these differences, findings are not in line with the results of Pantzer et al. and migrants did not seem to be adversely affected [22]. We found HRQoL levels were not lower in migrant children compared to native-born children. And there were no important differences in the other variables under study between the two groups. These results seem to be different compared to previous other European studies $[33,34]$, but similar to studies based in the United States [35]. We suggest that the force of selective migration may have changed in recent years. Germany has been receiving skilled workers, who despite their lower socioeconomic levels (compared to the native-born) report a high level of perceived health compared with previous migrants [12]. Indeed, selective migration may have become more accentuated following the 2008 economic crisis. However, this hypothesis cannot be tested with the data of our study, since data concerning duration of residence of migrants in Germany was not available. An alternative explanation of the results is based on life course trajectories of HRQoL. Our sample is based on young children and they are normally less affected by differences with peers, do not yet suffer bullying based on their migrant status, and have fewer problems adapting to a new language than older children [36,37].

Comparing the HRQoL mean score with other studies we see that our scores are lower compared with the scores reported by the German National Health Interview and 
Examination Survey for children and Adolescents (KIGGS) [20]. The children in our study were approximately $0.5-1$ standard deviations below the children with migrant backgrounds in the KIGGS study. Anyway, caution is warranted in interpreting these differences because the studies used different versions of the KK, ours based on self-reports, sampled children of different ages, and our study was not based on a nationwide random sample. However, our result is worrisome since studies show a trend towards a decrease in HRQoL with increasing age [38].

Some limitations of the study deserve comment. Our results are based on a kindergarten-based convenience sample from a central highly populated region in Germany. However, we consider our results have internal validity for comparisons between migrant children and native-born German children, i.e. similar selection factors for enrollment in the same kindergartens. The study has several strengths. To our knowledge, this is the first study that investigated HRQoL in kindergarten children predominantly with migrant backgrounds and in a self-reported fashion. HRQoL data was collected from multimodal sources of information: the children themselves, in addition to other data from the parents and the kindergarten teachers.

\section{Conclusion}

To our knowledge, this is the first study that measures HRQoL in young kindergarten children using self-reports that compare migrants and native-born children. Our results suggest that HRQoL at early ages has a different pattern than previous studies among migrant school children. However, these results should be further tested since the duration of residence of families in Germany was not available, and the sample has internal validity, but not external validity. Our findings underscore the need to study the life course trajectory of HRQoL among migrants. Since our study has exploratory character, further replication is warranted in representative samples, not least to improve management of HRQoL in young children with migrant background.

\section{Abbreviations \\ HRQL: Health related quality of life; EU: European Union; KK: Kiddy-KINDL; PERIK: Positive Development and Resilience in Daily Life of Kindergarten Children; WET: Vienna Developmental Test; KIGGS: German National Health Interview and Examination Survey for children and Adolescents.}

\section{Competing interests}

The authors declare that they have no competing interests.

\section{Authors' contributions}

EVO contributed to conception, performed the analysis of the data, wrote the manuscript, and was part of the study project. NvS contributed to conception, wrote the manuscript, designed the study project, and was part of the study project. CW and EK performed previous analysis of the data, and were part of the study project. IK made critical revisions and supervised the manuscript. CKH designed the study project, contributed to writing, made critical revisions, supervised the manuscript, and she was part of the study project. All authors read and approved the final manuscript.

\section{Acknowledgements}

This study was funded by the Niedersächsisches Institut für frühkindliche Bildung und Entwicklung (nifbe FP17-09), the Albert and Barbara von Metzler Stiftung, Frankfurt/Main and the Gemeinnützigen Hertie-Stiftung, Frankfurt/ Main.

Received: 21 January 2014 Accepted: 28 July 2014

Published: 3 August 2014

\section{References}

1. Acevedo-Garcia D, Almeida J: Special issue introduction: place, migration and health. Soc Sci Med 1982 2012, 75:2055-2059.

2. Flink IJE, Beirens TMJ, Looman C, Landgraf JM, Tiemeier $\mathrm{H}$, Mol HA, Jaddoe WW, Hofman A, Mackenbach JP, Raat H: Health-related quality of life of infants from ethnic minority groups: the generation R study. Qual Life Res 2013, 22:653-664.

3. García-Gómez P, Oliva J: Health-related quality of life of working-age immigrant population. Gac Sanit SESPAS 2009, 23(Suppl 1):38-46.

4. Puder J, Pinto AM, Bonvin A, Bodenman P, Munsch S, Kriemler S, Marques-Vidal P: Health-related quality of life in migrant preschool children. BMC Public Health 2013, 13:384

5. Urbanus-van Laar JJN, de Koning JS, Klazinga NS, Stronks K: Suboptimal asthma care for immigrant children: results of an audit study. BMC Health Serv Res 2008, 8:22.

6. Vieno A, Santinello M, Lenzi M, Baldassari D, Mirandola M: Health status in immigrants and native early adolescents in Italy. J Community Health 2009, 34:181-187.

7. Markides KS, Eschbach K: Aging, migration, and mortality: current status of research on the Hispanic paradox. J Gerontol B Psychol Sci Soc Sci 2005, 60 Spec No 2:68-75.

8. Viruell-Fuentes EA: Beyond acculturation: immigration, discrimination, and health research among Mexicans in the United States. Soc Sci Med 2007, 65:1524-1535

9. Ullmann SH, Goldman N, Massey DS: Healthier before they migrate, less healthy when they return? The health of returned migrants in Mexico. Soc Sci Med 2011, 73:421-428.

10. Akresh IR, Frank R: Health selection among new immigrants. Am J Public Health 2008, 98:2058-2064

11. Migration and migrant population statistics - Statistics Explained. [http://epp.eurostat.ec.europa.eu/statistics_explained/index.php/Migration_ and_migrant_population_statistics]

12. Villalonga-Olives E, Kawachi I: The changing health status of economic migrants to the European Union in the aftermath of the economic crisis. J Epidemiol Community Health 2014, 68:801-803.

13. Coddington RD: The signifcance of life events as etiologic factors in the diseases of children. I: a survey of professional workers. J Psychosom Res 1972, 16:7-18.

14. Bhugra D: Migration and mental health. Acta Psychiatr Scand 2004, 109:243-258.

15. Von Steinbüchel N, Wilson L, Gibbons H, Hawthorne G, Höfer S, Schmidt S, Bullinger M, Maas A, Neugebauer E, Powell J, von Wild K, Zitnay G, Bakx W, Christensen A-L, Koskinen S, Sarajuuri J, Formisano R, Sasse N, Truelle J-L, QOLIBRI Task Force: Quality of Life after Brain Injury (QOLIBRI): scale development and metric properties. J Neurotrauma 2010, 27:1167-1185.

16. von Steinbüchel N: Gesundheitsbezogene Lebensqualität als Beurteilungskriterium für Behandlungseffekte bei Patienten mit Epilepsie. Präv Rehabil Jahrg 1995, 7:139-146.

17. Startseite - Statistisches Bundesamt (Destatis). [https://www.destatis.de/ DE/Startseite.html]

18. Wals $M$, Hillegers $M H J$, Reichart $C G$, Verhulst $F C$, Nolen WA, Ormel J: Stressful life events and onset of mood disorders in children of bipolar parents during 14-month follow-up. J Affect Disord 2005, 87:253-263.

19. Jordanova V, Stewart R, Goldberg D, Bebbington PE, Brugha T, Singleton N, Lindesay JEB, Jenkins $R$, Prince $M$, Meltzer H: Age variation in life events and their relationship with common mental disorders in a national survey population. Soc Psychiatry Psychiatr Epidemiol 2007, 42:611-616.

20. Ravens-Sieberer $U$, Erhart M, Wille N, Bullinger M: Health-related quality of life in children and adolescents in Germany: results of the BELLA study. Eur Child Adolesc Psychiatry 2008, 17(Suppl 1):148-156.

21. Schenk L, Ellert U, Neuhauser H: Migration und gesundheitliche Ungleichheit. Public Health Forum 2008, 16:18.e1-18.e3. 
22. Pantzer K, Rajmil L, Tebé C, Codina F, Serra-Sutton V, Ferrer M, Ravens-Sieberer U, Simeoni M-C, Alonso J: Health related quality of life in immigrants and native school aged adolescents in Spain. J Epidemiol Community Health 2006, 60:694-698.

23. Homepage - Federal Statistical Office (Destatis). [https://www.destatis.de/ EN/Homepage.html]

24. Ravens-Sieberer $\mathrm{U}$, Bullinger $\mathrm{M}$ : Assessing health-related quality of life in chronically ill children with the German KINDL: first psychometric and content analytical results. Qual Life Res Int I Qual Life Asp Treat Care Rehabil 1998, 7:399-407.

25. Ravens-Sieberer U, Ellert U, Erhart M: Health-related quality of life of children and adolescents in Germany: norm data from the German Health Interview and Examination Survey (KiGGS). Bundesgesundheitsblatt Gesundheitsforschung Gesundheitsschutz 2007, 50:810-818.

26. Ravens-Sieberer U, Bullinger M: KINDL Manual homepage. [http://kindl.org/ english/]

27. Mayr T, Ulich M: Social-emotional well-being and resilience of children in early childhood settings-PERIK: an empirically based observation scale for practitioners. Early Years Int J Res Dev 2009, 29:45-57.

28. Kastner-Koller U, Deimann P: Wiener Entwicklungstest (WET). Göttingen: Hogrefe; 2002.

29. Van Agt H, Verhoeven L, Van Den Brink G, De Koning H: The impact on socioemotional development and quality of life of language impairment in 8-year-old children. Dev Med Child Neurol 2011, 53:81-88.

30. Veer L, Van der S, Kempers MJE, Last BF, Vulsma T, Grootenhuis MA: Quality of life, developmental milestones, and self-esteem of young adults with congenital hypothyroidism diagnosed by neonatal screening. J Clin Endocrinol Metab 2008, 93:2654-2661.

31. Von Rueden U, Gosch A, Rajmil L, Bisegger C, Ravens-Sieberer U: Socioeconomic determinants of health related quality of life in childhood and adolescence: results from a European study. J Epidemiol Community Health 2006, 60:130-135.

32. SAS Institute Inc: Base SAS 9.3 Procedures Guide. Cary, NC: SAS Institute Inc; 2011.

33. Jaeger FN, Hossain M, Kiss L, Zimmerman C: The health of migrant children in Switzerland. Int J Public Health 2012, 57:659-671.

34. Nakash O, Nagar M, Shoshani A, Zubida H, Harper RA: The effect of acculturation and discrimination on mental health symptoms and risk behaviors among adolescent migrants in Israel. Cultur Divers Ethnic Minor Psychol 2012, 18:228-238

35. Breslau J, Borges G, Tancredi DJ, Saito N, Anderson H, Kravitz R, Hinton L, Aguilar-Gaxiola S, Mora M-EM: Health selection among migrants from Mexico to the U.S.: childhood predictors of adult physical and mental health. Public Health Rep 2011, 126:361-370.

36. Analitis F, Velderman MK, Ravens-Sieberer U, Detmar S, Erhart M, Herdman $\mathrm{M}$, Berra S, Alonso J, Rajmil L: Being bullied: associated factors in children and adolescents 8 to 18 years old in 11 European countries. Pediatrics 2009, 123:569-577.

37. Derluyn I, Broekaert E, Schuyten G: Emotional and behavioural problems in migrant adolescents in Belgium. Eur Child Adolesc Psychiatry 2008, 17:54-62.

38. Palacio-Vieira JA, Villalonga-Olives E, Valderas JM, Espallargues M, Herdman $\mathrm{M}$, Berra S, Alonso J, Rajmil L: Changes in health-related quality of life (HRQoL) in a population-based sample of children and adolescents after 3 years of follow-up. Qual Life Res 2008, 17:1207-1215.

doi:10.1186/1471-2458-14-790

Cite this article as: Villalonga-Olives et al:: Health related quality of life of immigrant children: towards a new pattern in Germany? BMC Public Health 2014 14:790.

\section{Submit your next manuscript to BioMed Central and take full advantage of:}

- Convenient online submission

- Thorough peer review

- No space constraints or color figure charges

- Immediate publication on acceptance

- Inclusion in PubMed, CAS, Scopus and Google Scholar

- Research which is freely available for redistribution 